\title{
Teaching: instructor-student relationship, how it affects quality learning - the makings of a great RN students + instructor $=$ partnership
}

\begin{abstract}
I consider teaching as an art and a science. One may wonder why, but there is no manual for the esthetics (art) of teaching; not everyone can teach or be an effective nursing Instructor. I have been teaching since spring of 2012, happened by accident or did it? I have been asked on more than one occasion, "What is it that you are doing that students enjoy clinical so much?" Even though I have not been teaching for a long time, this question has become even more important because every clinical group I have taught inevitably has horror stories about past clinical instructors followed by "good instructors are hard to find". This is concerning because it should not be this way. Good nursing instructors should be the norm rather than an exception to the rule. As I pondered this issue over the weeks, I decided to write about what makes for a good nursing Instructor. I cannot see myself when I teach so I thought it would make for a better article writing about nursing students' perception of me as a clinical Instructor. All students in this article verbalized the need for something to be done, reiterating "we are paying good money for nursing education and not getting it;" "we know things will not change for us but if we can be part of change for future students then we want to do it." This article explores my beliefs about teaching, strategies I have used for teaching, coaching, and mentoring, highlighting three groups of nursing students' perspectives about my teaching style and the need for influencing change. In reviewing the literature on good teaching for this article I realized and much to my surprise that what I did by instincts and careful thought over the years as an instructor is supported by evidence. I teach three different clinical specialties as well as medical/surgical.
\end{abstract}

Volume 3 Issue 3 - 2015

\author{
Reezena H Malaska',2,3 \\ 'Trauma Critical Care RN, USA \\ ${ }^{2}$ Adjunct Professor, Notre Dame College, Cuyahoga Community \\ College, USA \\ ${ }^{3}$ Doctoral Student
}

Correspondence: Reezena Malaska,Adjunct Professor, Notre Dame College, Cuyahoga Community College, Cleveland/Akron, Ohio Area, USA, Email zeenamalaska@yahoo.com

Received: October 29, 2015 | Published: October 29, 2015

\section{Asking the question}

I love being a nurse, doing hands-on patient care, being a nursing instructor and more importantly advocating for what is right. No one has ever taught me how to be a nursing instructor. I have used my vast international education, experiences, skills and training, insights as a seasoned nurse to come up with what I believe is the equation for a student- nursing instructor relationship. Over the years, I have paid attention to what students want, what works for them, what does not work, their learning styles and most of allearly on I learned it is not a "one size fits all." Recently after listening yet again to 18 students (ADN and BSN) share their "bad Instructors" experiences I decided to write about my strategies for teaching. I shared my article topic saw how excited the students were, and mutually agreed they would be part of change. Some students I have taught specialties clinical since January, others clinical spanning 4-5 weeks. I asked for two opinions and posed the following questions: "As students, what is important to you?"

"What did you find that I did as an Instructor to make this a great clinical experience?"

\section{Group I Students}

a. "Extremely relatable and down to earth and shows that you really care and want us to experience as much as we can during a shortened clinical time; matching clinical experience with lecture material is extremely important and helps bring the two together." (Natalia)

b. "Ability to adapt to our way of teaching/learning is awesome; very down to earth and relatable; understanding our stresses; very knowledgeable and passionate about nursing, it makes me excited to be a nurse one day." (Stephanie) c. "Very knowledgeable and up-to-date evidence-based practices. I appreciate the autonomy our instructor has given us as 3rd semester nursing students. She did not constantly hold our hand and let us make informed, uncoerced decisions, as much as our student scope of practice allowed.” (Tammy)

d. "Teaches us empathy and kindness which allows us as nursing students to connect with our patients on a better level. Allows us to be independent and use critical thinking to evaluate our patient care experience and goals." (Leslie)

e. "Brings lecture material into clinicals and educates us on the material further. Easy to ask questions too and always available." (Katelyn)

f. "Allows us to be independent but available when we have a question or concern. Be approachable and enjoy nursing as a profession. Uses daily clinical or other experience to teach us and help further our nursing career." (Dina)

\section{Group 2 Students}

a. "I believe the most critical element you display as a successful clinical instructor is the fact that you truly care about the success of the students. You understand the importance of hands on experience during this time and how beneficial it is for us as students to relate what we learn in lecture with what we experience during clinicals." (Mikey)

b. "Creates an open and effective learning environment for students that make learning easier. Is invested in students success, going above and beyond to teach students using clinical studies and articles related to clinical experiences." (Jessica) 
c. "The environment that is provided to us is so positive, that it makes us students want to learn whatever we possibly can. All I want is to be the best nurse that I can be and by having a positive environment I can actually achieve that." (Lauren)

d. "As a student in your clinical, I appreciate the fact that you never talk in a demeaning way to us and welcome all of our questions. You demonstrate procedures and treatments before we have to perform them with our patients. Also, your positive attitude is contagious and makes your students excited to experience what nursing has to offer." (Kristi)

e. "Creating a great environment to learn in by always having things organized is important. Even when things are disorganized and chaotic it's important for the instructor to take charge and guide the students through it. It's important for the instructor to have a warm, friendly attitude, and also to be approachable for any questions students may have." (Evelyn)

\section{Group 3 Students}

a. "You take what we are learning in class and make it come full circle for us in clinicals. You listen to our input about what we want to learn and make it happen! You increase my selfconfidence in my skills, and that causes me to feel like a real nurse." (Christina)

b. "I really appreciate how you take time out of your day to thoroughly explain disease processes and how they affect the patient." I also like how in post-conference you bring in information and visuals from outside sources. I am a very visual and hands on person, so it really helps me." (Kelsey)

c. "I like when my instructor helps me make connections between one illness and another, and how each system affects the body as a whole. I also like that you let us be very hands on; it helps me with my skills and learning by performing the skills, not just observing another RN." (Cait)

d. "I like how she throws us into the environment and lets us work hard with the nurses and let us find our way. She prepares us for many scenarios and makes sure that we are comfortable." (David)

e. "You are relatable. You know our skill levels and push us to do our best with the knowledge we know to provide quality patient care. There are no dumb questions when talking with you. It's great to have an instructor that is all about helping students succeed rather than making us feel stupid when we don't know something or forget." (Julia)

f. "It is helpful to feel comfortable discussing weaknesses with our instructor who is excited about working on them with you. Trust in nursing instructor allows students to feel confident and excited about new experiences in the clinical setting. Positive feedback and constructive criticism can determine the potential of the students." (Alex)

\section{Reflections from a former Nursing Student}

"I met Ms. Malaska during my critical care nursing rotation. She was very supportive and a wonderful clinical instructor and mentor. Ms. Malaska was very encouraging and helped me overcome many challenges I faced in nursing school. She always respected our feelings and empowered us. It is no wonder that after graduation and passing my NCLEX RN exam, she was the first person I called to share the great news with. As I continue to develop into my role as a registered nurse in the ICU, I still keep in touch with Ms Malaska because I look up to her as my role model. She continues to provide me with great advice, support and encouragement." (Didi BSN, RN).

\section{What is nursing in the 2 lst century of Healthcare Delivery?}

Nursing is a practice discipline with multiple definitions depending on who the writer is and their philosophy. According to Nightingale's Notes on Nursing written in 1859, the patient is the center around which all care is designed to meet their individual needs and the environment manipulated so that the patient can attain a healthy state. ${ }^{1}$ Florence Nightingale was passionate about nursing, her caring, kindness, and compassion was evident in her works in treating the soldiers.

I learned the art and science of nursing with caring an integral part three decades ago. Nursing in the old days used to be "task oriented" but over the years has evolved to embrace nursing science (theories, concepts, and models) as the guiding force for evidencebased practices. Fast forward to nursing today, we work in a fast paced environment besieged with high technology driven equipment, clinical decision systems, information and communication systems, and processes just to name a few. The Institute of Medicine (IOM) report called for healthcare organizations and professional groups to promote healthcare delivery that is safe, effective, client centered, timely, efficient, and equitable (2001). Furthermore, in a followup report the IOM Committee ${ }^{2}$ recommended that all healthcare professionals must be educated, skilled, and collaborate as part of an interdisciplinary care team using evidence-based practices, quality improvement approaches and informatics to deliver patient centered care. As nurses we are constantly adapting to the changing needs of our environment. Then why would nursing instructors not ensure that our nursing students receive the best possible education, training, and skills to meet the demands for the 21 st century of patient centered healthcare delivery?

\section{The instructor-nursing student relationship: the nursing process}

There are many similarities between caring for an assignment of patients new to the nurse and taking on the responsibility of teaching a new group of nursing students. A long time ago, I had this idea, why not apply the same principles of the nursing process that we use in caring for patients to teaching a group of nursing students. The ultimate goal of each situation is for good outcomes. Let me refresh our memories, the nursing process is the model nurses were trained to use to guide patient care. The model includes assessment, planning, implementation and evaluation with re-evaluation. The nurse-patient relationship begins from the first moment of meeting the patient and I firmly believe the instructor - nursing student relationship begins from that first meeting. This first meeting inevitably sets the tone for the ensuing relationship that follows in both situations. Applying the nursing process to each individual student guides in meeting that individual student's learning needs and helps them to grow into becoming confident, skilled and mentally prepared the role of registered nurse. Evaluation and re-evaluation occurs each clinical day and allows for prioritizing and setting new goals or learning needs. Once one goal is met we move onto another.

The first day of clinical I spend a few minutes getting to know each student. For example, I will ask students to tell me a little bit about themselves (personal) ask about their last clinical experience and what they hope to get out of current clinical rotation. Students are often very nervous and have preconceived ideas about the new 
Instructor based on past unsavory experiences. This reaction is similar to the patient whom has had a negative care experience which shapes their entire view of current care. As nurses we must spend the time and effort to show caring and to reassure patients that we are going to provide the best possible care. The same principles apply to students. If we do not show students we care, how are they going to know it, how are they going to feel comfortable and trust us, how will they have a positive and accomplished clinical experience? We cannot fake caring, it comes from within!

\section{What makes for a good nursing instructor?}

I tell my students on that first day, "What you put into it is what you will get out of it". If you show me enthusiasm and a zest for learning then you are in the right place with the right instructor. I emphasize professionalism, communication and all the expectations that go along with behaviors and uniform in the clinical setting. I model the behaviors I expect of my students. I let my students know on that first day that I usually leave the clinical area twice, once to get coffee and the second time to use the bathroom. Everyone including unit staff always know where I am. I do what I call hourly rounding on my students, more often for the first few days of clinical to give them the support they need. The goals are similar to purposeful rounding for patients. I believe by making myself visible and available they will be reassured that I am there for them, ready, willing and able to answer a question, help with a task, redirect or clarify. I do not hover, I try to encourage some form of independence, instills trust and confidence in my students. Their confidence and self-esteem level grow and is evident from one week to the next. It is a beautiful thing to see. Many students have shared "instructors tell us not to go on the unit" that they must wait in the facility reception area for the instructor each clinical day. I do not believe in this practice, students are adult learners and should be treated as such with professionalism and respect, trusted to do the right thing. ${ }^{3}$ There is nothing wrong with going to the unit and waiting for the instructor in the staff break room or locker room.

Instructions for each clinical day is clear at the beginning of the day, similar to outlining the day to my patient and what they can expect. This action decreases anxiety and everyone knows the "tentative" plan (does not always work out) for going to lunch, for post-conference or what I will be teaching in post conference. Students are often anxious about an upcoming test or quiz, this is my opportunity to reassure them that I will review the suggested topics in post conference. I find this strategy helps to decrease their anxieties and they can refocus fully on clinical learning. I am very observant and in tune with each student. I usually ask first thing in the morning how everyone is then address the individual needs to make sure I am getting their fullest attention to optimize and direct their learning. Students appreciate this. One student said to me, "I like that you have to have your cup of coffee in the morning and that you encourage us to stop for a few minutes to get a coffee and grab a snack, you are like the only instructor that does that". I will often take them (whoever is available) with me to go get a coffee and come right back to the unit to resume "working". If we do not take care of each other, show our human side how are we going to work together in partnership, develop that strong teamwork? Caring is not just in nursing, caring should be extended for each other at work, our colleagues, out of work and more importantly caring for ourselves. ${ }^{4,5}$ If we cannot care for ourselves, how can we give the very best to caring for our patients and their families?

If we do not encounter a clinical experience for a disease process, I will teach by simulation, explaining the concepts using evidence based practices. For example, we had not seen an asthma pediatric patient in 4 weeks of being on the floor, so I did a thorough review of asthma in post conference. The next clinical day a student had an asthma patient and did not ask a single question much to my surprise. When she presented her patient in post conference I asked how come she did not ask me any questions, she reminded me that she felt fully prepared to take care of the patient based on my review and was able to carry out all care including patient teaching. She recalled feeling like a "real nurse" because she knew what to do.

I utilize story-telling to explain and demonstrate concepts and disease processes to tie in pathophysiology with the clinical setting both in clinical and post conferences. I match clinical experiences with what is being taught in didactic in the classroom. That was how I learned decades ago. I encourage students to use SBAR on a daily basis and work with them to become comfortable with this concept. For example, I will ask students "tell me about your patient" using SBAR to guide the conversation. Students love this way of teaching. I use a real patient situations in clinical for "just in time" learning, often using simulation to demonstrate the worst case scenario. Students are encouraged to do a short 5 minutes presentation of their patients in post conference using the SBAR format and I will expand teaching by explaining the pathophysiology of the past medical history and how it relates or affects current diagnosis and treatment. We utilize reflection on a daily basis to reinforce learning. Three years ago, when I first started teaching a faculty member gave me one of the best advice she encouraged me to have students verbalizing a negative followed by a positive experience to end our day. I have been using this strategy ever-since to end post conference and find it very successful, we love it. Most students will not have a negative but have several positives to reflect on. I will give "high fives" or a "Yay" and clap when a student demonstrates critical thinking or has achieved a goal. I use humor or my own silliness to get students to laugh. ${ }^{6}$

Effective instruction demands teaching and learning strategies individualized to meet the particular student needs much like the patient-centered care I give as a bedside nurse. We all have different styles and rates of learning and understanding. Some of us are more visual than others and there are others that have the ability to read an article and understand it the first time but may be lacking in applying the concepts in the real patient setting. I support this style because I have always been a visual learner. I teach the way I would have wanted to be taught all those years ago. I manipulate the environment to support and enhance learning.

\section{There is a Method to My "Madness"}

I model the behaviors that I expect my students to follow bydemonstrating amongst other things interdisciplinary teamwork and caring. For example, if the unit I am on is busy or a patient's call light, pump or alarms go off and no one is available I will answer it. I am a nurse first and should always be mindful that we are there to take care of the patients first, provide the best possible care. Just because I am an instructor does not mean I should walk past a call light or ignore a beeping pump. If a family member or any other person come up to me with a question I try to help or find someone who can. If the phones are ringing and the secretary is busy or staffs are busy I answer the phones too. Staffs appreciate this and will make the effort to help and teach students when I am busy with another student. I have been known to go from one floor to another on my own initiative in a specialty clinical looking for pumps or equipment for the nursing staff during busy times.I cannot sit back and watch nurses run around during those busy times when I can be doing something to help. I engage, redirect, and guide my students during these times, making the most of every single learning opportunityand at the same time support the nursing staff that are supporting student learning. Students 
will reflect that although it was really busy they felt like "real nurses". It's a "win-win" situation all around.

I am very protective of my students and will do whatever it takes to ensure the environment is conducive to learning. In situations whereby it is not, I work very closely with students to guide, support, and protect. I use negative behaviors, or personality clashes that we may come across as a teachable moment of how to negotiate a hostile environment. The nursing profession is fraught with bullying behaviors, lateral violence and conflicts. A hostile work environment is detrimental to patient care and safety, can cause medical errors ensuing in poor patient satisfaction or poor outcomes. Communication, interdisciplinary collaboration, and teamwork are essential to promoting a culture of safety and ensuring a safe productive work environment. Students need to be guided on how to manage and navigate such an environment because we are expected to work in an environment that supports a culture of safety. ${ }^{7}$ How can we show caring to patients, turn around and be so mean to our co-workers/colleagues? We cannot fake caring, it comes from within!

\section{The "Cheesecake Effect"}

I am sure you are wondering what cheesecake has to do with this article. I love to bake and cook and usually share that I am a very good cheesecake (from scratch) baker in my introduction to a new group of students. Inevitably, the request always comes you have to make one for us. I have been baking cheesecakes not only for my students but the clinical units/sites I teach at for the past three years (there have been many). It has been a big hit, ice breaker especially in those hard to get to know clinical areas winning staff over so my students can have good clinical experiences. I do it as a surprise when they least expect it. I taught one group as a substitute instructor and on the second occasion with them I baked an amaretto cheesecake with strawberry and blackberry toppings and brought it in. They were surprised but what surprised me the most is one student's comments, "usually it is us who are always bringing in treats and goodies for the nurses, no one has ever done anything like this for us". This says it all. I am not saying to go and bake cheesecakes for your students but a little treat goes a long way in showing caring and kindness along with being true to teaching our future generation of nurses.

As an instructor, students are my first priority, much like patients are my priority in bedside care. It is all about the students, and not about me, just as the patient is central to everything we do as nurses. I emphasize the positives and work to guide students in the right direction. There is no such thing as a stupid question, I encourage questions and I frame questions to encourage dialog and guide critical thinking. I've learned in reviewing the evidence for this article that emphasizing the positives is similar to Leddy's ${ }^{8}$ theory of healthiness that we must view human strengths as resources and working from the approach of mobilizing our human strengths we can easily conquer our weakness thereby promoting health, wellbeing and quality of life. My approach may not always work there will be some individuals that no matter what you do are beyond being reached. I advocate doing the very best, reconcile that the best has been done and let it go. Some are just too caught up in the "drama" and like being in that mode so we just cannot win them all.

\section{Conclusion}

Students want to learn and they want an instructor that will collaborate with them. Give them the tools to be successful, let them be empowered, let them see you are human too. Be authentic, approachable, available and enthusiastic, accountable, responsible, communicate respectfully at all times, and encourage sharing what they are learning to be a better nurse. Feedback is important, what you say and how you say it goes a long way towards enhanced learning. We have a moral and ethical responsibility to provide the teaching, coaching and mentoring that comes with the title of nursing Professor or Instructor. Make post conference an amiable dynamic teaching/discussion, inject some humor into it, encourage storytelling, tell it using SBAR, reflection, state the negative and positive of the day, making sure to leave on a positive note. Set them up for success not failure.I teach using a combination of art and science learned from nursing school and over the years using a dash of emotional intelligence, mindfulness, empathy, trust, and positive communication, guided by my moral compass, ethic of care, and a big dose of Watson' ${ }^{4}$ human caring focusing on my strengths and abilities as a nurse, patient advocate and student advocate. Happy students make for happy instructors makes for a strong nursing team providing the best patient centered care to our patients. ${ }^{9,10}$

\section{My disclaimer}

The information, opinions expressed in this presentation is solely those of the author/presenter and not those of The Metro Health System or any affiliated company or organization. The Metro Health System does not guarantee the accuracy or reliability of the information provided here in.

\section{Conflicts of Interest}

The authors do not have any Conflict of interests.

\section{Acknowledgments}

None.

\section{Funding}

None.

\section{References}

1. Zaccagnini ME, White KW. The Doctor of Nursing Practice essentials: A new model for advanced practice nursing. 2nd edn, Jones \& Bartlett Publishers, Sudbury, USA. 2014

2. Institute of Medicine (IOM). Crossing the quality chasm. A new health system for the 21 st century. National Academies Press, Washington, DC, USA. 2003.

3. Hayden-Miles M. Humor in clinical nursing education. Journal of Nursing Education. 2002;41(9):420-428.

4. Watson J. Jean Watson's theory of human caring. In: Parker ME, Editor Nursing theories and nursing practice. 2nd edn, F. A. Davis, Philadephia, USA. 2006;295-302.

5. Watson J. Nursing: The philosophy and science of caring. Little, Brown, Boston, USA. 1979.

6. Joint Commission. Joint Commission. Behaviors that undermine a culture of safety. 2008

7. American Nurses Association (ANA). Incivility, Bullying, and Workplace Violence. 2015.

8. Leddy SK. Integrative health promotion: Conceptual bases for nursing practice. Jones \& Bartlett Publishers, Sudbury, USA. 2006.

9. Alligood MR. Nursing theorists and their work. (8th edn.) Mosby, St Louis, USA. 2014; p. 786.

10. Sorbello B. The nurse administrator as caring person; a synoptic analysis applying caring philosophy, Ray's Ethical theory of existential, authenticity, the ethic of justice and the ethic of care. International Journal of Human Caring. 2008;12(1):44-49. 